\title{
JOVENS SUPERDOTADOS NA EDUCAÇÃO SUPERIOR: UM DESAFIO PARA A DOCÊNCIA
}

Denise Maria de Matos*

Laura Ceretta Moreira**

Cleuqa Kubn ***

\begin{abstract}
RESUMO: O estudo trata das políticas de identificação e cuidado de jovens superdotados no contexto de uma universidade pública brasileira. O objetivo geral da pesquisa foi investigar se os professores universitários reconhecem os alunos superdotados, como o fazem e quais as estratégias metodológicas que adotam para a sua inserção educacional na universidade. Baseado nos pressupostos teóricos da pesquisa qualitativa, foram entrevistados professores do Ensino Superior. Como resultado, verificou-se que a invisibilidade desses estudantes ocorre tanto na sua precária identificação nas políticas nacionais, como na falta de locus nas universidades que apoiem suas especificidades educacionais. A falta de formação na universidade sobre a temática da superdotação impacta diretamente a prática pedagógica dos professores, que demonstram dificuldades em identificá-los como público-alvo da Educação Especial.
\end{abstract}

PALAVRAS-CHAVE: Altas habilidades/superdotação. Educação superior. Professor universitário. Inclusão educacional.

\section{GIFTED YOUNG PEOPLE IN HIGHER EDUCATION: A CHALLENGE FOR TEACHING}

\begin{abstract}
This study examined the policies for the identification and attendance of gifted young students in the context of a Brazilian public university. The main objective of the research was to investigate whether university professors identify gifted students, how they do it and what teaching strategies they develop for inclusive education of gifted students at the university. Results showed that the invisibility of these students occurs both in their precarious identification in national policies, and in the lack of locus in universities that support their educational specificities. Likewise, the lack of training at the university on the subject of giftedness, directly impacts the teaching strategies of professors with these students, who demonstrate difficulties in identifying them as special education students.
\end{abstract}

KEYWORDS: High abilities/giftedness. Higher education. College professor. Inclusive education.

\footnotetext{
* Doutorado em Educação (UFPR); Integra a Equipe Técnico-Pedagógica do Departamento de Educação Especial da SEED/PR. Colaboradora do Núcleo de Pesquisas e Práticas em Altas Habilidades/Superdotação (NEPAHS-UFPR e no Laboratório de Políticas e Práticas em Altas Habilidades/Superdotação (LAPEAHS-UFPR). Compõe a Diretoria do Conselho Brasileiro para Superdotação - CONBRASD. E-mail frdmatos@,uol.com.br / ORCID: 0000-0001-7844-7265.

** Doutorado em Educação (USP); Professora do PPGE-UFPR; Coordenadora de Inclusão e Diversidade da UFPR; Pesquisadora do Núcleo de Pesquisas e Práticas em Altas Habilidades/Superdotação (NEPAHS-UFPR); Coordenadora do Laboratório de Políticas e Práticas em Altas Habilidades/Superdotação (LAPEAHS-UFPR). Líder do Grupo de Pesquisa Educação Inclusiva/ Educação Especial: Políticas, Práticas e Processos de Desenvolvimento Humano. Presidente da Comissão Técnica Científica do Conselho Brasileiro para Superdotação - CONBRASD. E-mail lauracm@,ufpr.br ORCID 0000-0003-4569-7369.

*** Doutoranda em Educação (UFPR); Mestre em Educação (UFPR). Professora da Rede Estadual de Ensino do Estado do Paraná. Professora no Centro Universitário UDC. Pesquisadora do Laboratório de Políticas, Pesquisas e Práticas Educacionais em Altas Habilidades/Superdotação (LAPEAHS-UFPR). Pesquisadora do Grupo de Pesquisa Educação Inclusiva/ Educação Especial: Políticas, Práticas e Processos de Desenvolvimento Humano. E-mail cleokuhnoficial@gmail.com

ORCID: 0000-0001-6595-7135
} 


\section{Introdução}

O Censo do Ensino Superior, realizado em 2019 e publicado em 2020 pelo Instituto Nacional de Estudos e Pesquisas Educacionais Anísio Teixeira (Inep), aponta que o número total de estudantes que ingressaram nas Instituições de Ensino Superior (IES) foi de 8,6 milhões. Com relação às matrículas em cursos de graduação de alunos com deficiência, transtornos globais do desenvolvimento ou altas habilidades/superdotação ${ }^{1}$ (AH/SD) somaram juntas o número de 48.520 estudantes, ou seja, apenas $0.56 \%$ do montante de estudantes matriculados. Do total geral de matrículas, 1.551 foram identificadas com $\mathrm{AH} / \mathrm{SD}$, o que indica $0.18 \%$. Isto por si só demonstra o quanto os dados referentes a esses estudantes são subdimensionados no Ensino Superior brasileiro, já que, segundo PÉREZ (2007), a Organização Mundial da Saúde (OMS) estima que um percentual de 3,5\% a 5\% da população possui superdotação, o que indica a necessidade de concretizarmos estudos sobre esse público no Ensino Superior.

Sendo assim, o objetivo geral foi investigar se os professores universitários reconhecem estudantes com altas habilidades/superdotação, como o fazem e que estratégias metodológicas adotam para a inclusão educacional destes na universidade. Portanto, é neste escopo que o presente estudo se constitui.

Com isso, buscamos na voz do professor universitário uma melhor compreensão acerca do processo de inclusão do aluno superdotado no Ensino Superior, tendo como lócus de pesquisa uma universidade pública da região sul brasileira.

Duas questões básicas nos moveram a estruturar a pesquisa nesta perspectiva:

a) Quais são as concepções dos professores universitários sobre altas habilidades/superdotação?

b) Os professores entrevistados identificam alunos que apresentam altas habilidades/superdotação?

A discussão sobre as informações que professores universitários possuem acerca do tema "altas habilidades/superdotação", bem como a verificação de como se dá o reconhecimento desse grupo de estudantes pelos docentes subsidiaram a análise dos dados.

Neste estudo, utilizamos os pressupostos da pesquisa qualitativa, diante da possibilidade de expressar uma melhor compreensão das práticas pedagógicas de professores universitários. Foram

\footnotetext{
${ }_{1}^{1}$ Para Rangni e Costa (2011), a área das altas habilidades/superdotação apresenta questões polêmicas com relação ao uso de nomenclaturas ou termos que a defina. A barra oblíqua na terminologia indica que os termos são equivalentes, permitindo a variação no uso dos termos: altas habilidades, altas habilidades/superdotação, superdotação e/ou superdotados com a mesma conotação, indicando o mesmo perfil de sujeito nesse texto.
} 
balizados por indicativos da Análise de Conteúdo, sobretudo aqueles evidenciados nos estudos de Bardin (2009) e Minayo (2003).

\section{Altas habilidades/superdotação na educação brasileira}

É apenas na década de 1970 que o sistema educacional brasileiro institui indicativos, por meio da Lei no 5.692/71, para a implantação de ações em prol das altas habilidades/superdotação. Mesmo que este aporte legal tenha sido insuficiente para que a área desencadeasse políticas efetivas no cenário nacional, reconhecemos sua importância histórica. A partir da década 1990 e das duas primeiras décadas anos 2000, a veiculação de documentos internacionais, como a Declaração Mundial de Educação para Todos (UNESCO, 1990), a Declaração de Salamanca (UNESCO, 1994), a Declaração de Incheon (UNESCO, 2015), e, ainda, de documentos nacionais, como a Lei de Diretrizes e Bases para Educação Nacional - LDBEN no 9.394/96, o Parecer 17/2001 -CNE, a Resolução CNE/CEB 4/2009, o Plano Nacional de Educação (2014-2024), somado aos aportes legais dos Estados e Municípios brasileiros, traz, mesmo que de modo distinto, concepções inclusivas de Educação Especial.

São inúmeras as mazelas enfrentadas para garantir a inclusão educacional, que vão desde as desigualdades sociais à precária formação inicial de professores para atender a diferença e a diversidade, que contam com a incipiente qualificação dos recursos humanos em serviço até os precários recursos financeiros para aquisição de materiais que apoiem as especificidades de estudantes que fazem parte dessa modalidade educacional.

Afora estes aspectos, apontamos que, no contexto da Educação Especial, a fragilidade na área da superdotação na perspectiva inclusiva é duplamente atingida: de um lado, pela pouca visibilidade desse público nos documentos internacionais e nacionais, se comparada às discussões e encaminhamentos de políticas públicas de outras áreas de abrangência da Educação Especial; do outro, há o enfrentamento diante da efetivação das políticas públicas e da constante luta pelos direitos dos estudantes superdotados enquanto público-alvo da Educação Especial no contexto educacional.

Podemos afirmar que, no Brasil, o foco da Educação Especial sempre esteve mais intensamente voltado para as deficiências e os transtornos, ou seja, o caráter complementar da Educação Especial tem recebido mais atenção do que o suplementar.

As pessoas com altas habilidades têm sua identidade distorcida, ou seja, perante a sociedade elas ainda não conseguiram firmar-se enquanto pessoa com Altas Habilidades, fazendo com que essa identidade fique apenas no imaginário das pessoas, o que leva a dificultar sua real "visualização". Tudo isso, porque, para uma parcela da sociedade, elas não passam de mitos, o que dificulta sua identificação e, consequentemente, seu encaminhamento para um atendimento especializado que, por vezes, é questionado e visto como desnecessário. (FREITAS; RECH, 2006, p. 61). 
Estudos realizados por Gardner (1995; 1998; 2000), por meio da teoria das Inteligências Múltiplas (IM), permitiram respostas inovadoras sobre a inteligência humana, ampliando e redimensionando o conceito de altas habilidades/superdotação, as formas de sua identificação e o próprio fazer do trabalho pedagógico com esses estudantes. Para exemplificar, apontamos o quanto a identificação/avaliação dessas pessoas, que antes se restringiam às avaliações clínicas, mediante aplicação de testes psicométricos para verificar o "Quociente de Inteligência" (QI), passa a acrescentar a importância de uma identificação por meio da observação direta dos comportamentos, com uma visão pluralista da mente humana, a qual aponta para o fazer pedagógico singular, que precisa tornar os ambientes do convívio do estudante, em especial o ambiente escolar, focos para compreender suas especificidades.

Estudos de Gardner (1995; 2000), Renzulli, Hartman e Callahan (1975), Renzulli (1997; 2004; 2001; 2014), Renzulli et al (2001), Renzulli, Gentry e Reis (2003), e Sternberg (2009) contribuíram muito para esta proposta de identificação do superdotado e, consequentemente, para atuação pedagógica com esse alunado. Observamos que as diretrizes de políticas públicas nacionais destinadas a essa demanda também começaram a considerar pressupostos elencados por esses autores.

Em 2005, o Governo Federal lançou uma importante política pública em prol do atendimento de alunos superdotados que frequentam a educação pública básica: os Núcleos de Atividades para Altas Habilidades/Superdotação - NAAH/S, esta proposta surge como uma alternativa de se criar espaços voltados para a identificação, atendimento, estimulação do potencial dos alunos da rede pública de ensino. Na sequência, é publicada a Portaria Ministerial 13/2007, da extinta SEESP (Secretaria de Educação Especial), que aborda sobre o atendimento educacional especializado (AEE) aos alunos público-alvo da Educação Especial, o qual é definido como espaço organizado com materiais didático-pedagógicos, equipamentos e profissional especializado em Educação Especial.

A partir do documento supracitado, é no AEE que devem ser desenvolvidas atividades de ampliação e/ou suplementação de conteúdos por meio das Salas de Recursos Multifuncionais (SRM), que também contemplam estudantes com altas habilidades/superdotação.

Por sua vez, a Política Nacional de Educação Especial na Perspectiva da Educação Inclusiva (BRASIL, 2008) recomenda a permanência do aluno com altas habilidades/superdotação no ensino comum, com apoio especializado, atendimento em salas de recursos multifuncionais, em contraturno, para participar de atividades de enriquecimento curricular. Acrescentamos às propostas de atendimento previsto nas políticas públicas os grupos da sociedade civil organizada, que prestam serviços importantes para a área, dentre eles, destacamos o "Conselho Brasileiro para Superdotação" - CONBRASD, criado em 2003, que entre seus inúmeros objetivos está o compromisso de promover e divulgar ações que 
atendam às necessidades de caráter social e educacional das pessoas com altas habilidades/superdotação no Brasil ${ }^{2}$

Embora as políticas estejam sendo implementadas e difundidas por vários estados brasileiros, percebemos que as ações que contemplam o referido alunado se concentram no âmbito da educação básica. As salas de recursos multifuncionais, os núcleos de atividades, todos foram organizados e estão prescritos para atender alunos superdotados até o ensino médio.

Ao revisar os sites das Instituições públicas de Ensino Superior, observamos que duas universidades apresentam programas, núcleos e/ou laboratórios que atuam em ações de ensino, pesquisa e extensão ligados às altas habilidades/superdotação.

A Universidade Federal Fluminense (UFF), em 1992, criou o Programa de Atendimento para Alunos com Altas Habilidades/Superdotação (PAAAH/SD), que articula ações de ensino, pesquisa e extensão e objetiva realizar diagnósticos, orientações à família e à escola, atendimento educacional especializado, aceleração de estudos, formação docente e pesquisa. Neste sentido, busca soluções individuais e coletivas a partir da identificação das demandas sociais apontadas pelas famílias de alunos com altas habilidades/superdotação da educação básica e alunos da UFF, que procurem o programa para a formação docente. O público-alvo dos $\mathrm{PAAAH} / \mathrm{SD}$ está voltado para estudantes de escolas públicas e privadas, trata-se de um programa gratuito e se caracteriza como apoio pedagógico, não como substitutivo da escolarização (UFF/PAAAH/SD, 2021³).

A UFPR, em 2016, criou o Núcleo de Estudos e Práticas em Altas Habilidades/Superdotação (NEPAHS), que até o ano de 2019 atuou em parceria com a PUC/PR. O NEPAHS, além de se constituir num projeto de extensão, faz parte do Núcleo de Apoio às Pessoas com Necessidades Especiais (NAPNE). É constituído por professores, alunos de graduação e pós-graduação e profissionais colaboradores da comunidade. O NEPAHS foi instituído para fortalecer o histórico de ações que a UFPR possui na área de Altas Habilidades/Superdotação desde 2006 e, sobretudo, para desenvolver ações de política institucional para $\mathrm{AH} / \mathrm{SD}$ na universidade, garantindo um espaço de reflexão e discussão sobre a temática e, assim, desenvolvendo projetos e ações geradoras de visibilidade e inclusão desse alunado na universidade, uma vez que eles apresentam demandas pedagógicas diferenciadas e peculiares (MOREIRA; RIECHI, 2020).

Em 2020, é criado, também na UFPR, o Laboratório de Políticas, Pesquisas e Práticas Educacionais em Altas Habilidades/Superdotação (LAPEAHS), que é ligado ao Grupo de Pesquisa Educação Inclusiva/Educação Especial: Políticas, Práticas e Processos de Desenvolvimento Humano. O Laboratório é constituído por pesquisadores da área da educação da UFPR, da Universidade Federal de Santa Maria (UFSM), da Universidade do Estado do Amazonas (UEA), bem como por pesquisadores colaboradores, estudantes de graduação e pós-graduação. É um espaço de reflexão, produção acadêmica

\footnotetext{
2 https:// conbrasd.org/index.php

${ }^{3}$ http://paaahsd.uff.br.
} 
e de formação transversal da educação básica ao ensino superior. Os seguintes eixos temáticos na área de altas habilidades/superdotação fazem parte das discussões do LAPEAHS: Inclusão e Políticas Educacionais; Identificação e Avaliação; Atendimento Educacional Especializado (AEE); Relação Família e Contexto Educacional (https://www.facebook.com/LaPEAHS/).

Com relação às políticas educacionais destinadas à acessibilidade e inclusão nas universidades públicas, destacamos o Programa Incluir, criado em 2005 e implementado até 2011, por meio de Chamadas Públicas, realizadas pela SEESP e SESU, que apontavam a criação e consolidação dos Núcleos de Acessibilidade, visando eliminar barreiras físicas, pedagógicas, nas comunicações e informações, nos ambientes, instalações, equipamentos e materiais didáticos nas Instituições Federais de Ensino Superior (IFES). A partir de 2012, o Programa passa a apoiar projetos das IFES, com aporte de recurso financeiro, diretamente, previsto na matriz orçamentária das Instituições de Acessibilidade. $\mathrm{Na}$ sequência, o Programa Incluir é incorporado ao Programa Nacional de Assistência Estudantil (PNAES) e a distribuição de seus recursos é definida pelas IFES. Por conta da institucionalização do Programa Incluir, grande parte das universidades públicas brasileiras iniciam a organização de seus núcleos de acessibilidade e, desta forma, começam a regulamentar suas ações para o público da Educação Especial, porém com o foco maior em estudantes que apresentam deficiências, demonstrando a inexistência de políticas públicas para estudantes com altas habilidades/superdotação no Ensino Superior.

\section{Sobre os procedimentos para realização da pesquisa}

A problemática das altas habilidades/superdotação no Ensino Superior tem sido pouco explorada no campo educacional, o que demonstra a possibilidade de ampliação de pesquisas posteriores acerca deste tema. O contexto de realização do estudo se deu em sete cursos de graduação de uma universidade pública localizada na região sul do Brasil.

O critério que definiu os participantes da pesquisa foi, inicialmente, elencar cursos em que havia estudantes identificados com altas habilidades/superdotação. Obtivemos a indicação dos cursos, bem como do contato dos estudantes superdotados por meio de informações cedidas pelo Núcleo de Apoio às Pessoas com Necessidades Especiais $\left(\mathrm{NAPNE}^{4}\right)$, pois esse Núcleo oferece alternativas de inclusão às pessoas com deficiência físico-motora, baixa visão, cegos, surdocegos, surdos, transtorno do espectro autista (TEA) e altas habilidades/superdotação.

O registro de estudantes indicado pelo referido Núcleo apontou alunos matriculados nos seguintes cursos: Ciências Biológicas, Engenharia de Bioprocessos e Biotecnologia, Medicina, Psicologia, Engenharia Química, Administração e Pedagogia.

\footnotetext{
${ }^{4}$ http://www.prograd.ufpr.br/portal/cepigrad/napne.
} 
De posse dos dados, fizemos contato individual com vinte e três estudantes listados para apresentação da proposta da pesquisa e para obter indicação dos professores para entrevista, onze retornaram o contato indicando professores que poderiam ser entrevistados. Ressaltamos que, a pedido dos estudantes, o sigilo de suas identidades foi mantido, sob a alegação de que não gostariam de expor a condição de altas habilidades/superdotação aos seus professores e colegas, exceto um que já havia feito esse comunicado para alguns docentes.

Aplicado o critério inicial para indicação dos entrevistados, o outro critério para proceder o convite aos professores foi o tempo de serviço na universidade. Estabelecemos que o entrevistado deveria ter, no mínimo, 5 (cinco) anos de docência na Instituição e, com isso, dos 11(onze) professores, 9 (nove) atenderam aos critérios e aceitaram participar do estudo. Finalmente, foram realizadas entrevistas semiestruturadas, em locais e horários agendados de acordo com a possibilidade de cada um.

Os nomes dos entrevistados, apresentados neste documento, são fictícios, preservando a identidade dos participantes. A caracterização dos participantes se definiu por profissionais com o tempo de docência variando entre 05 (cinco) e 40 (quarenta) anos e com formação em diversas áreas do conhecimento, dentre as quais estão: ciências biológicas, humanas, tecnológicas, exatas, saúde e sociais aplicadas. No grupo dos nove entrevistados, identificaram-se profissionais com mais de um curso de graduação. Cumpre salientarmos que tanto estudantes como professores aprovaram e assinaram o Termo de Consentimento Livre Esclarecido (TCLE).

\section{Análise, resultados e discussão dos dados}

A análise e interpretação dos dados foram balizados por indicativos da Análise de Conteúdo, sobretudo aqueles evidenciados nos estudos de Bardin (2009) e Minayo (2003). Portanto, trabalhamos com categorias agrupando as ideias, elementos ou expressões capazes de abranger de forma ampla os aspectos que possuem características comuns, homogeneidade ou se relacionam entre si na investigação realizada. Nesta análise, foi construído um conjunto de categorias descritivas, aqui relacionadas nos dois eixos de pesquisa, a saber: concepção e conhecimento a respeito das altas habilidades/superdotação; avaliação de aprendizagem e prática pedagógica do professor.

Desvelar o cotidiano do professor, para compreendermos melhor a permanência de estudantes com altas habilidades/superdotação no complexo contexto universitário, foi o que nos levou à estruturação desta análise.

\section{Concepção e conhecimento sobre altas habilidades/superdotação}

Com objetivo de compreender se os professores entrevistados tinham ciência de que os estudantes com altas habilidades/superdotação fazem parte do público que compõe a Educação Especial, conforme regem os documentos oficiais, indagamos a eles o que segue: "Você considera o aluno 
superdotado como público da Educação Especial? Se a resposta for sim, que tipo de necessidade educacional especial ele pode apresentar"?

Dois professores responderam que o superdotado faz parte do grupo dos alunos com necessidades educacionais especiais. Dos demais, dois responderam que o superdotado não participa do grupo de alunos com necessidades especiais e cinco ficaram em dúvida em afirmar ou negar a indagação, pois não tinham informações suficientes. Dentre as afirmações dos professores que indicaram características dos estudantes superdotados, elencamos as falas dos professores Mariana e Leonardo: “[... demandam curiosidade e o aprofundamento [...]." (Mariana); “[...] sempre com muitas perguntas, sempre querendo levar para frente. [...]” (Leonardo). Por outro lado, a professora Juliana enfatiza que a pessoa com superdotação poderá ter dificuldades de se concentrar “[...] naquilo que, já não é mais novidade, então se você não apresenta um desafio ela não vai trazer nenhuma adição, ficará entediada [...]” (Juliana).

Posto o que foi dito pelos professores, enfatizamos dois aspectos, o primeiro diz respeito ao primeiro propósito da educação de superdotados que, segundo Renzulli (2014), é fornecer aos jovens o máximo de oportunidades para a autorrealização por meio do desenvolvimento e da expressão de uma área ou de uma combinação de áreas de desempenho, em que o potencial superior possa estar presente. (RENZULLI, 2014).

O outro aspecto é de cunho legal, visto que a questão do enriquecimento curricular para o Ensino Superior está prevista tanto na Lei no 12.796/ $2013^{5}$ como na Resolução CNE/CEB 4/2009. Esta última indica em seu artigo $7^{\circ}$ que as instituições de Ensino Superior e institutos devem voltar o enriquecimento curricular ao desenvolvimento e promoção da pesquisa, das artes e dos esportes.

De igual forma, tanto a Política Nacional de Educação Especial na Perspectiva inclusiva (BRASIL, 2008), quanto Resolução CNE/CEB 4/2009 (BRASIL, 2009), consideram que estudantes com $\mathrm{AH} / \mathrm{SD}$ são aqueles que apresentam um potencial elevado e grande envolvimento com as áreas do conhecimento humano, isoladas ou combinadas: intelectual, liderança, psicomotora, artes e criatividade.

Todavia as respostas indicadas pelos docentes entrevistados demonstram que, assim como os professores da educação básica, os que atuam no Ensino Superior também possuem pouca formação e conhecimentos sobre altas habilidades/superdotação. O fato de apenas dois dos nove professores entrevistados afirmarem que esse alunado apresenta necessidades educacionais especiais e relacionarem a importância do enriquecimento curricular, a aceleração de estudos e características específicas a essa demanda, demonstra o quanto a incipiente identificação dessas pessoas na educação básica, a falta de políticas públicas para essa área e de formação inicial e/ou continuada ainda é um dos grandes gargalos para sua invisibilidade e exclusão, que se estende ao Ensino Superior.

A característica apontada pela professora Juliana a respeito da busca por novos desafios, por novidades para que se sinta motivado, Renzulli et al. (2001), elenca como uma das características

\footnotetext{
${ }^{5}$ Lei que revisou a LDBEN 9.394/96.
} 
motivacionais "una conducta persistente cuando se interesa por um tema o problema".

Bergamin (2018, p. 35), ao descrever as características do superdotado com perfil criativo, diz que "[...] aplica habilidades em áreas de problema e estudo que tenham relevância pessoal e em níveis desafiadores de atividades investigativas", aproximando-se do que disseram Mariana e Leonardo.

O segundo questionamento realizado versou o seguinte: "Em sua opinião, quais são os comportamentos característicos de um aluno superdotado em situações de aprendizagem?”. O professor Rafael enfatizou a nota e o desempenho dos estudantes nas avaliações e exemplificou a questão do IRA (Índice de Rendimento Acadêmico), que é um dos aspectos indicados no histórico individual dos estudantes. Para o professor há alunos com excelentes IRA $(0,97$ ou 0,98$)$, por exemplo, com muita facilidade no estudo e nos demais aspectos da aprendizagem “[...] porque é a nota que vai mostrar [...] são muito críticos [...] pessoa com facilidade de aprender [...]”.

Mesmo que muitos estudantes com AH/SD apresentem notas ou conceitos altos, esse comportamento não deve ser considerado como marca padrão e determinante em todos esses sujeitos, pois, segundo Pérez e Freitas (2014)

[...] a frequente associação equivocada das $\mathrm{AH} / \mathrm{SD}$ ao desempenho escolar extraordinário, à criatividade, à precocidade, ou à genialidade, de forma isolada, provoca muita confusão na identificação e banaliza o conceito teórico que deve ser definido, esclarecido e explicitado nos documentos educacionais (PÉREZ; FREITAS, 2014, p. 635).

Ao indicar o perfil do estudante que se destaca por suas notas, como uma "associação equivocada das AH/SD", as autoras Pérez e Freitas (2014) não descaracterizam os que apresentam o perfil acadêmico, como mencionou Rafael em sua resposta, ao exemplificar os que se destacam pelo IRA, mas evidenciam pesquisas que indicam superdotados que apresentam dificuldades na utilização das características que conduzem ao alto desempenho, também chamados de underachivers. Superdotados underachivers, nos estudos de Ourofino e Fleith (2011), são descritos por uma "baixa performance acadêmica, destacam-se o tédio, os conflitos constantes com pares e professores, a baixa autoestima, a incapacidade de generalizar e aplicar seus conhecimentos e o baixo rendimento escolar" (p. 211).

Mariana destaca vários comportamentos que os superdotados podem apresentar na aprendizagem. Todos esses comportamentos se comprovam nos estudos da área.

[...] originalidade, é a criatividade [...] acúmulo de conhecimento [...] acúmulo teórico de conhecimento sistematizado em várias áreas [...] ele é diferente, pela maneira com que ele resolve os problemas [...] chama atenção, e não é na profundidade ou na qualidade, não é, é na forma de abordar aquele conhecimento, aquela opinião, aquele ponto de vista. [...] envolvimento com a tarefa [...] o cara é brilhante, mas ele não consegue cumprir o programa [...] (Mariana). 
A criatividade abordada por Mariana está presente em estudos que descrevem os conceitos e a caracterização das altas habilidades/superdotação:

Já as habilidades cognitivas referem-se à fluência para gerar novas ideias e respostas, à flexibilidade, à originalidade e à elaboração detalhada sobre determinado tema. Estes são ingredientes necessários para a criatividade, que junto com os traços de personalidade da pessoa, podem favorecer a demonstração desta característica. Entre os principais traços, pode-se citar a autonomia, a flexibilidade pessoal e abertura à experiência (NEGRINI, 2018, p. 77).

Por mais que a criatividade seja uma característica peculiar à pessoa com altas habilidades/superdotação, ainda assim, essa característica demanda estímulos e é preciso que sejam dadas oportunidades para que o sujeito a expresse. Remoli e Capellini (2017) realizaram um estudo para verificar registros de práticas que estimulem a criatividade em estudantes com altas habilidades/superdotação, no período de 2005 a 2015. Como resultado, "verificou-se que a temática que mais se repetiu foi a comparação da criatividade em alunos com e sem AH/SD, especialmente tendo alunos do Ensino Fundamental como público-alvo" (p. 455). Com isso, evidencia-se a necessidade de intensificação dos estudos voltados para uma melhor compreensão dos comportamentos de superdotação em jovens universitários e que contribuam com ações assertivas no atendimento às peculiaridades desse público.

Os professores Rafael e Frederico abordam a velocidade de raciocínio e a rapidez na aprendizagem como características que, se não forem trabalhadas pelos professores, podem inclusive desmotivar o estudante, pois "os conteúdos ficam triviais, ele não tem necessidade de estudar em casa, ele já absorveu tudo dentro de sala de aula, e aí acaba se desmotivando porque aquilo é rotineiro [...]” (Leonardo). O professor ainda adverte sobre a rapidez de processamento de informações, visto que esse estudante: "consegue processar bem rapidamente e absorver informações e aquilo que é a média de uma aula de duas horas para captar, de repente, ele consegue em um tempo bem menor". A capacidade de síntese, de associação de ideias e do olhar interdisciplinar desses estudantes é apontado pelo professor Frederico: "O aluno passa pela análise, que é a capacidade de ler um texto e decompor, e depois sintetizar isso diferente, trazendo como se fosse um ímã [...] enxergando além das barreiras [...]”.

No escopo das legislações brasileiras, o Decreto n 7.611/ 2011, que dispõe sobre o atendimento educacional especializado na Educação Especial, em seu art. $1^{\circ}$, trata do dever do Estado com a educação das pessoas público-alvo da Educação Especial, e uma das diretrizes aponta para a necessidade de se adotar medidas de apoio individualizadas e efetivas, em ambientes que maximizem o desenvolvimento acadêmico e social dos estudantes como uma forma de se atingir uma inclusão plena. Neste sentido, compreendemos que a sala de aula pode ser um dos loci mais favoráveis para os estudantes desenvolverem sua aprendizagem a partir de suas especificidades. Quando a questão inclui estudantes com superdotação, é fundamental que estratégias educacionais sejam lançadas. Maia-Pinto e Fleith (2004) advertem que 
práticas educacionais como enriquecimento, a compactação, a modificação ou diferenciação e a aceleração curricular de estudantes que apresentam superdotação precisam ser consideradas.

\section{O processo de avaliação e o fazer pedagógico do docente frente à superdotação}

Os aspectos anteriormente levantados nos trazem para a discussão da prática pedagógica do professor universitário, especialmente no que se refere ao processo de avaliação, na formação de estudantes com altas habilidades/superdotação. Neste sentido, solicitamos aos professores que comentassem sobre o seu fazer pedagógico/práticas educacionais, sobretudo a avaliação da aprendizagem de estudantes que apresentam altas habilidades/superdotação, para que pudéssemos extrair as categorias de análise.

Com relação ao fazer pedagógico dos docentes, observamos que seis entrevistados apontam que é necessário a presença de práticas educacionais específicas, que vão desde a intensificação de tarefas e conteúdos, [...] "Onde o professor deveria dar um ou dois passos além e preparar um material específico para esse aluno" [...] "que ele poderia ser um dos tutores" [...] "que adiantasse alguma disciplina direcionada para seu interesse" [...] "até mesmo que esse aluno com superdotação", conforme apontado pelo professor Fernando, "pudesse servir como tutor junto às escolas de educação básica” [...]. O professor Henrique chama atenção para o ensino baseado em problemas e para a interação entre professor e aluno, pois [...] “isso aqui gera comprometimento”. Santos, Silva e Machado (2014) ressaltam a urgência de direcionarmos nossas ações pedagógicas para o reconhecimento e o estímulo ao talento de estudantes com Altas Habilidades/ superdotação. Na fala do professor Fernando, é possível perceber o reconhecimento do potencial do estudante com superdotação e a busca de estratégias que contemplem suas especificidades.

Dois dos docentes entrevistados indicam a importância de rever o fazer pedagógico e o quanto seria desafiador ter um estudante superdotado em sala de aula, porém sentem-se despreparados para tal. Mariana diz [...] "que o aluno superdotado me puxa para buscar sempre ser mais original [...]". O professor Leonardo adverte para a falta de capacitação dos docentes universitários nesta temática [...] "não me sinto capacitado, eu não sei como fazer isso, se eu tivesse auxílio eu adoraria fazer” (Leonardo). Por sua vez, dois professores apontam que não são necessárias alterações em seu fazer pedagógico, pois [...] "ele vai aprender tudo aquilo que a gente tem que passar pra turma só que com mais facilidade” (Eliana). O professor Rafael acredita que mudar suas práticas pedagógicas poderia gerar conflito entre os alunos, pois [...] "o restante da turma não aceitaria que fosse feito um diferencial para aquele aluno que eu considero especial". Sobretudo o pensar do professor Rafael demonstra a falta de reconhecimento acerca dos direitos das pessoas com altas habilidades/superdotação e, como lembra Titon (2019), a percepção envolta no mito de que estudantes com altas habilidades/superdotação estão relacionadas/os “a um dom, 
ao privilégio de ter além" (p. 70) reforça a condição da não necessidade de investimentos para o seu atendimento.

Quando os docentes foram questionados sobre a necessidade ou não de estudantes com superdotação receberem avaliações diferenciadas na universidade, foi possível evidenciarmos estratégias e posicionamentos diferenciados. Para o professor Fernando, deve-se fugir da avaliação tradicional com esse alunado devido às suas grandes habilidades: “o que melhor funciona para esse aluno é avaliação através de projetos, ele deve elaborar um projeto longo, denso, e ser avaliado pelo projeto ou pela obra que fizer, dependendo das várias áreas do conhecimento”. A estratégia levantada pelo professor Fernando aponta para a importância de se reconhecer e estimular o potencial de alunos superdotados. Com referência à avaliação tradicional, que, muitas vezes, prioriza provas e exames, Luckesi (2011) afirma que eles sempre ocorreram e continuam a ocorrer em separado dos atos pedagógicos de ensinar e aprender. Porém, a avaliação não se dá dessa forma, nem se pode dar, sob pena de não ser avaliação. Ela é parte do ato pedagógico, formando um todo com os atos de planejar e executar.

Estudos sobre a avaliação da aprendizagem de estudantes do Ensino Superior estão se intensificando, mas o tema continua sendo um desafio que põe à prova, muitas vezes, o grande empenho dos docentes na formação dos profissionais, como bem aponta Pedrochi Júnior et al. (2021):

A educação, nas diferentes etapas da vida das pessoas, assume objetivos diferentes, a avaliação também compartilha dessas sutilezas de modo que, na Educação Superior, o sistema de avaliação deve ser planejado para o adulto, em um contexto de profissionalização, ou seja, considera-se a formação de um profissional, em que se espera o desenvolvimento de um conjunto de competências e habilidades - perfil do egresso - e a avaliação pode possibilitar o acompanhamento de como esse processo ocorre, bem como fomentá-lo (PEDROCHI JÚNIOR et al., 2021, p. 50).

Sobre avaliação, um aspecto relevante a ser considerado, independentemente de se ter estudantes com altas habilidades/superdotação na sala de aula, é trazido pela professora Mariana sobre a importância de se organizar critérios diferenciados nas avaliações, ao invés de avaliações diferenciadas. Segundo as palavras da entrevistada: "não posso ter uma avaliação diferenciada, eu talvez buscasse critérios diferenciados de avaliação, mas eu nunca tive essa prática, mas eu acho que seria isso, mudar o critério".

Frederico chama atenção para as dificuldades de se efetivar mudanças quando o sistema educacional se ajusta a partir de formas fechadas e tradicionais, visto que em sua fala aponta que tentou realizar avaliações a partir das dinâmicas em grupo, porém, foi chamado atenção pela chefia e que passou a aplicar provas escritas e de múltipla escolha, todavia "ainda assim eu consigo de os 100 pontos dar 20 pontos de dinâmica de grupo [...]". Adverte que estimula o aluno, além disso "poderia trazer muito mais benefícios, teorias, contribuir para que ficasse mais satisfeito".

Diante dos impasses sobre diferenciação de currículo ou de avaliação, retornamos aos princípios equitativos e ressaltamos que o alinhamento entre as estratégias de ensino e avaliação precisam ser 
consideradas na prática pedagógica. No entanto, há situações em que a avaliação engessada anula o processo de aprendizagem, pois, "motivação e manutenção de engajamento" do estudante do Ensino Superior no processo de aprendizagem conduzem a uma avaliação de caráter progressivo e com feedbacks sistemáticos (PEDROCHI JÚNIOR et al., 2021).

Por outro lado, os professores Leonardo e Henrique apontam que não deveria haver nenhum tipo de alteração na avaliação quando temos estudantes com altas habilidades/superdotação na universidade. Leonardo diz que a avaliação não deveria ser modificada, "ela precisa ser igual para todos". De acordo com Henrique, a avaliação não deve ser alterada e "deve ser dada uma nota e a nota é feita uma prova" [..] e complementa "nossa forma de avaliação é injusta" (Henrique).

Para Fleith (1999), a ideia de que o aluno superdotado tem recursos suficientes para desenvolver habilidades e produzir conhecimento é um mito que se reflete no uso limitado de práticas educativas direcionadas a esta demanda.

\section{Conclusão}

Diante da discrepância demonstrada pelo Censo do Ensino Superior publicado pelo Inep, entre o número de estudantes matriculados no Ensino Superior, o índice de sujeitos que podem apresentar altas habilidades/superdotação e o número de estudantes identificados atualmente, descritos no início desse texto, consideramos que discussões dessa temática refletem em desconforto, uma vez que os números indicam a insipiência no envolvimento da comunidade acadêmica. $\mathrm{O}$ alto nível de formação dos professores universitários nem sempre determina ou garante o conhecimento acerca dos comportamentos humanos, em especial, no que se refere às diferenças e necessidades que os sujeitos podem apresentar para a aprendizagem.

Sendo assim, coube-nos, nesse estudo, a investigação sobre o conhecimento de professores universitários acerca de estudantes com altas habilidades/superdotação e, também, a identificação de possíveis práticas pedagógicas e avaliativas adotadas para viabilizar a formação desses sujeitos. Dentre os aspectos evidenciados, foi possível apontar que mesmo a universidade pública sendo, sobretudo nos últimos anos, um importante espaço para acesso ao público da Educação Especial, de modo mais específico, após a promulgação da Lei n ${ }^{\circ}$ 13.409/2016, que institui as cotas para pessoas com deficiência, é fundamental que estabeleça políticas e práticas institucionais que agreguem a permanência de todos os estudantes em suas especificidades. Neste sentido, os/as estudantes com altas habilidades/superdotação possuem particularidades educacionais que necessitam ser conhecidas e instituídas, dentre elas, a identificação e o reconhecimento da importância do enriquecimento, modificação e aceleração curricular.

As respostas obtidas para as indagações, e que deram o start desse estudo, foram analisadas à luz de pesquisas e estudos consolidados, o que permitiu compreender a concepção dos professores universitários entrevistados sobre altas habilidades/superdotação, bem como, aspectos relacionados à 
identificação e às estratégias metodológicas adotadas para trabalhar com esses estudantes. Observamos que informações sobre o tempo de docência na universidade, área de formação e de atuação não se mostraram determinantes quanto ao nível de conhecimento dos entrevistados acerca da caracterização, das especificidades para aprendizagem e do direito à Educação Especial de estudantes superdotados.

Estudantes com altas habilidades/superdotação compõem o público-alvo da Educação Especial, o que deveria garantir-lhes a identificação e o atendimento às condições específicas que apresentam para aprendizagem, em todos os níveis de ensino. Ao mensurar "público da Educação Especial", comumente se relaciona às pessoas com deficiências e/ou com problemas que interferem na aprendizagem, o que demonstra desconhecimento sobre o direito à inclusão de estudantes com altas habilidades/superdotação.

É urgente que as universidades brasileiras criem núcleos e/ou unidades de apoio educacional aos estudantes com altas habilidades/superdotação, que colaborem na identificação desses estudantes e de suas especificidades educacionais, assim como incentivem a promoção de informação e formação, sobretudo, de seus professores nesta área. A invisibilidade e a falta de políticas e práticas educacionais destinadas a esses estudantes é uma forma de destituí-los de seus direitos e necessitam serem revertidas por princípios inclusivos.

\section{REFERÊNCIAS}

BARDIN, Laurence. Análise de conteńdo. Lisboa, Portugal: Edições 70, 2009.

BERGAMIN, Aletéia Cristina. C. Enriquecimento curricular na classe comum a partir das necessidades de alunos com altas habilidades/superdotação.127f. Dissertação (Mestrado) -Universidade Estadual Paulista, Faculdade de Ciências, Bauru, 2018. Disponível em: https://repositorio.unesp.br/bitstream/handle/11449/153376/bergamin ac me bauru.pdf?sequence =3\&isAllowed $=\mathrm{y}$. Acesso em: 09 set. 2021.

BRASIL. Lei $n^{\circ}$ 13.409/2016. Altera a Lei no 12.711, de 29 de agosto de 2012, para dispor sobre a reserva de vagas para pessoas com deficiência nos cursos técnico de nível médio e superior das instituições federais de ensino. Disponível em http://www.planalto.gov.br/ccivil 03/ ato20152018/2016/lei/113409.htm. Acesso em: 20 fev. 2021.

BRASIL. Decreto $n^{\circ} 7.611$ de 17 de novembro de 2011. Dispõe sobre a educação especial, o atendimento educacional especializado e dá outras providências. Presidência da República/Casa Civil/ Subchefia para Assuntos Jurídicos. Brasília, DF, 2011. Disponível em: http://www.planalto.gov.br/ccivil 03/ ato2011-2014/2011/decreto/d7611.htm. Acesso em: 12 maio 2021. 
BRASIL. CNE. CEB. Resolução n. 4, de 2 de outubro de 2009, que institui diretrizes operacionais para o atendimento educacional especializado na educação básica, modalidade educação especial. Brasília: 2009.Disponível em: http://portal.mec.gov.br/dmdocuments/rceb004 09.pdf. Acesso em: 12 maio 2021.

BRASIL. Ministério da Educação. Secretaria de Educação Especial. Política Nacional de Educação Especial na Perspectiva da Educação Inclusiva. Brasília: MEC/SEESP, 2008. Disponível em:

http://portal.mec.gov.br/arquivos/pdf/politicaeducespecial.pdf. Acesso em: 10 jun. 2021.

BRASIL. Conselho Nacional de Educação. Parecer 17/2001, de 3 de julho de 2001. Diretrizes Nacionais para a Educação Especial na Educação Básica. Brasília: CNE, 2001. Disponível em:

http://portal.mec.gov.br/cne/arquivos/pdf/CEB017 2001.pdf. Acesso em: 09 jun. 2021.

BRASIL. Lei de Diretrizes e Bases da Educação Nacional no 9.394, de 20 de dezembro de 1996. Brasília: 1996. Disponível em: http://www.planalto.gov.br/ccivil 03/leis/19394.htm. Acesso em: 10 jun. 2021.

BRASIL. Lei no 5.692, de 11 de agosto de 1971. Fixa Diretrizes e Bases para o ensino de $1^{\circ}$ e $2^{\circ}$ graus, e dá outras providências. Poder Executivo. Diário Oficial [da] República Federativa do Brasil. Brasília, DF, 12 ago. 1971. Disponível em: https://www2.camara.leg.br/legin/fed/lei/1970-1979/lei-5692-11agosto-1971-357752-publicacaooriginal-1-pl.html. Acesso em: 25 nov. 2020.

FLEITH, Denise de Souza. Psicologia e educação do superdotado: definição, sistema de identificação e modelo de estimulação, Cadernos de Psicologia, n. 5, p. 37-50. 1999. Disponível em:

https://www.cadernosdepsicologia.org.br/index.php/cadernos/article/view/42. Acesso em: 09 set. 2021.

FREITAS, Soraia Napoleão; RECH, Andréia Jaqueline Devalle. Uma revisão bibliográfica sobre os mitos que envolvem as pessoas com altas habilidades. In: FREITAS, Soraia Napoleão (Org.). Educação $e$ Altas Habilidades/Superdotação: a ousadia de rever conceitos e práticas. Santa Maria: Ed. da UFSM, 2006. p. 61-87.

GARDNER, Howard. Inteligências múltiplas: a teoria na prática. Tradução de Maria Adriana Veríssimo Veronese. Porto Alegre: Artes Médicas, 1995.

GARDNER, Howard. Inteligência: múltiplas perspectivas. Tradução de Maria Adriana Veríssimo Veronese. Porto Alegre: Artes Médicas, 1998.

GARDNER, Howard. Inteligência: um conceito reformulado. Tradução de Adalgisa Campos da Silva. Rio de Janeiro: Objetiva, 2000.

LUCKESI, Cipriano Carlos. Avaliação da aprendizagem. São Paulo: Cortez, 2011.

MAIA-PINTO, Renata Rodrigues; FLEITH, Denise de Souza. Avaliação das práticas educacionais de um programa de atendimento a alunos superdotados e talentosos. Psicol. Esc. Educ., Campinas, v. 8, n. 1, p. 55-66, jun. 2004. Disponível em:

http://pepsic.bvsalud.org/scielo.php?script $=$ sci arttext\&pid=S1413$\underline{85572004000100007 \& \operatorname{lng}=\mathrm{pt \& nrm}=\text { iso. }}$. Acesso em: 03 set. 2020.

MINAYO, Maria Cecília de Souza (Org.). Pesquisa social: teoria, método e criatividade. 22 ed. Rio de Janeiro: Vozes, 2003.

MOREIRA, Laura Ceretta; RIECHI, Tatiana Isabele Jaworski de Sá. Ações afirmativas para inclusão no ensino superior de jovens com altas habilidades/superdotação: em foco a Universidade Federal Do 
Paraná. In: SÁ, A. C. M. Acessibilidade e inclusão no ensino superior: reflexões e ações em universidades brasileiras [E-book]. Goiânia: Cegraf UFG, 2020.

OUROFINO, Vanessa Terezinha Alves Tentes; FLEITH, Denise de Souza. A condição underachievement em superdotação: definição e características, Psicologia: Teoria e Prática, São Paulo, v. 13, n. 3, p. 206-222, 2011. Disponível em: https://pepsic.bvsalud.org/scielo.php?script=sci arttext\&pid=S151636872011000300016. Acesso em: 10 set. 2017.

PEDROCHI JÚNIOR, Osmar et al. Avaliação da aprendizagem no ensino superior: reflexões em uma perspectiva andragógica, Revista Ensino, Educação e Ciências Humanas, v. 22, n. 1, p. 43-51, 2021.

Disponível em: https://seer.pgsskroton.com/index.php/ensino/article/view/8902. Acesso em: 15 jan. 2021.

PÉREZ, Susana Graciela Pérez Barrera. Inclusão para superdotados. Ciência Hoje, v. 41, n. 245, p. 8-11, 2007. Disponível em: http://cienciahoje.uol.com.br/revista-ch/revista-ch-2008/245. Acesso em: 19 abr. 2021.

PÉREZ, Susana Graciela Pérez Barrera; FREITAS, Soraia Napoleão. Políticas públicas para as altas habilidades/superdotação: incluir ainda é preciso, Revista Educação Especial, v. 27, n. 50, set./dez. p. 627639. 2014. Disponível em: https://periodicos.ufsm.br/educacaoespecial/article/view/14274. Acesso em: 09 set. 2021.

RANGNI, Rosemeire; COSTA, Maria Piedade Resende da. Altas habilidades/superdotação: entre termos e linguagens, Revista Educação Especial, v. 24, n. 41, p. 467-482, 2011. Disponível em: https://periodicos.ufsm.br/educacaoespecial/article/view/3056. Acesso em: 28 ago. 2021.

REMOLI, Taís Crema; CAPELLINI, Vera Messias Fialho. Relação entre criatividade e altas habilidades/superdotação: uma análise crítica das produções de 2005 a 2015, Rev. bras. educ. espec., v. 23, n. 3, p. 455-470, 2017. Disponível em https://doi.org/10.1590/s1413-65382317000300010. Acesso em: 20 abr. 2021.

RENZULLI, Joseph. A concepção de superdotação no modelo dos três anéis: um modelo de desenvolvimento para a promoção da produtividade criativa. In: VIRGOLIM, Angela Maria R.; KONKIEW ITZ, Elisabete Castelon (Orgs.). Altas habilidades/superdotação, inteligência e criatividade. Campinas, SP: Papirus, 2014. p. 219-264.

RENZULLI, Joseph. O que é esta coisa chamada superdotação, e como a desenvolvemos? Uma retrospectiva de vinte e cinco anos, Educação, v. 22, n. 1, p. 75 - 131, jan./abr. 2004. Disponível em; https://www.marilia.unesp.br/Home/Extensao/papah/o-que-e-esta-coisa-chamada-superdotacao.pdf. Acesso em: 16 set. 2019.

RENZULLI, Joseph; GENTRY, Marcia; REIS, Sally. Enrichment clusters: a practical plan for realword, student-driven learning. Connecticut: Creative Learning Press, Inc. P.O. Box 320, Mansfield Center, 2003.

RENZULLI, Joseph. Enriching curriculum for all students. Illinois: SkyLight Training and Publishing Inc Arlington Heights, 2001.

RENZULLI, Joseph et al. Scales for rating the behavioral characteristics of superior students. Tradução espanhol de Juan A. Alonso, Yolanda Benito Mate, Susana Guerra e Camino Pardo. Salamanca: Amarú, 2001. 
RENZULLI, Joseph. The National Research Center on the Gifted and Talented: the dream, the design, and the destination. Gifted Child Quarterly, v. 2, n. 35, p. 73-80, 1997. Disponível em: https://scihub.se/https://doi.org/10.1177\%2F001698629103500205. Acesso em: 14 abr. 2019.

RENZULLI, Joseph; HARTMAN, Robert; CALLAHAN, Carolyn. Scale for Rating the behavioral characteristics of superior students. In: BARBE, W. B.; RENZULLI, J. S (Orgs.). Psychology and education of the gifted. 2 ed. New York: John Wiley \& Sons, 1975, p. $264-273$.

SANTOS, Amanda Oliveira; SILVA, Débora Pereira; MACHADO, Andrezza Belota Lopes. Estimulando os indivíduos com comportamento de altas habilidades/superdotação: da identificação ao atendimento educacional. In: MARQUEZINE, Cristina; CONEGLIAN, Andre Luis Osório; ALMEIDA, Josiane Junia Facundo (Orgs.). Discussões sobre deficiência física: linguagem, sala de recurso e altas habilidades/superdotação. São Paulo: Marquezine \& Manzini (ABPEE), 2014. p. 135-150.

STERNBERG, Robert. Psicologia cognitiva. São Paulo: Cengage CTP, 2009.

TITON, Eliane Regina. Estudantes com altas habilidades/superdotação na universidade: análise de itinerários pedagógicos. 2019. Dissertação. 210f. (Mestrado em Educação), Programa de Pós-Graduação em Educação, Universidade Federal do Paraná, Curitiba, 2019. Disponível em: https://acervodigital.ufpr.br/handle/1884/66307? show=full. Acesso em: 09 set. 2021.

UNESCO. Declaração Mundial sobre Educação para Todos: plano de Ação para Satisfazer as Necessidades Básicas de Aprendizagem. Unesco: Jomtien, 1990.Disponível em: https://abres.org.br/wpcontent/uploads/2019/11/declaracao mundial sobre educacao para todos de marco de 1990.pdf. Acesso em: 15 set. 2020.

UNESCO. Declaração de Salamanca: sobre princípios, políticas e práticas na área das necessidades educativas especiais. Brasília: CORDE, 1994. Disponível em: http://portal.mec.gov.br/seesp/arquivos/pdf/salamanca.pdf. Acesso em: 20 jan. 2020.

UNESCO. Declaraşão de Incheon. Educação 2030: rumo a uma educação de qualidade, inclusiva e equitativa à educação ao logo da vida para todos. Unesco: Coréia do Sul, 2015. Disponível em: https://pt.unesco.org/fieldoffice/brasilia/expertise/education-2030-brazil. Acesso em: 20 jan. 2021.

Recebido em: 18 de maio de 2021. Aprovado em: 18 de agosto de 2021. 